\title{
Driving Forces Analysis of Power Consumption in Beijing Based on LMDI Decomposition Method and LEAP Model
}

\author{
Dong Jun, Palidan Ainiwaer*, Liu Yao \\ School of Economics and Management, North China Electric Power University, Beijing, China \\ Email address: \\ dongjun624@126.com (Dong Jun),1182206070@ncepu.edu.cn (P. Ainiwaer),120192206101@ncepu.edu.cn (Liu Yao) \\ ${ }^{*}$ Corresponding author
}

To cite this article:

Dong Jun, Palidan Ainiwaer, Liu Yao. Driving Forces Analysis of Power Consumption in Beijing Based on LMDI Decomposition Method and LEAP Model. American Journal of Electrical Power and Energy Systems. Vol. 9, No. 1, 2020, pp. 14-25. doi: 10.11648/j.epes.20200901.12

Received: April 20, 2020; Accepted: May 8, 2020; Published: May 14, 2020

\begin{abstract}
With increasing pressure on resources and environment, sustainable development is becoming more and more important. As the largest energy consumer in the world, China needs to take measures to achieve energy transformation more urgently both from supply and demand side, which is of great significance for sustainable development and achieving carbon emissions target. In recent years, the capital city Beijing has also made great efforts to promote the replacement of electric energy in residential heating, manufacturing, transportation, power supply and consumption. In order to explore driving forces of total power consumption in Beijing's final demand sectors, this paper decomposes the factors into industrial electricity substitution effect, industrial energy intensity effect, industrial structure effect, economic scale effect, population structure effect, residential electricity substitution effect, residential energy intensity effect and population size effect based on the logarithmic mean Divisia index (LMDI) decomposition method. The decomposition results show that the industrial electricity substitution effect made the largest contribution to increase power consumption in Beijing's final energy consumption sector, followed by economic scale effect, residential energy intensity effect, population scale effect and residential electricity substitution effect, and other's effect does the opposite. Finally, seven different scenarios are set up to forecast the future power consumption of Beijing 's final sectors based on the long-term energy alternative planning model (LEAP), which reveals the impact of energy efficiency improvement and electricity substitution polices on electricity consumption in Beijing `s final energy consumption sectors.
\end{abstract}

Keywords: Driving Forces, Electricity Consumption, LMDI Decomposition Method, LEAP Scenario Analysis, Electricity Substitution

\section{Introduction}

As the largest energy consumer in the world, China faces serious air pollution problems, such as smog appearing in many cities - mainly caused by coal burning and exhaust emissions of motor vehicles-while industrialization and urbanization are still rapidly advancing in the country [1]. Therefore, it is urgent for china to take measures to achieve transformation of energy system from both supply and demand side, such as the energy structure upgrades from fossil fuels to renewables in energy supply sector and electricity substitution of end use sectors [2]. To reduce reliance on fossil fuels in end-use, the Chinese government has introduced a series of measures in some policy documents for the purpose of encouraging electrification, which covers numerous fields, such as residential heating, transportation, and industrial and agricultural production (National Development and Reform Commission, 2016a). Beijing, the capital city of china have great population and energy consumption, which urgently need to take measures to mitigate the carbon emissions for its sustainable development [3]. Beijing has actively promoted electricity substitution in various fields to achieve energy transformation in demand side. In residential heating, 407,700 households in 904 rural villages converted from coal to electricity, and more than 1.1 million households in the city had electricity heating customers. In transportation, 103 electric bus charging stations was built to meet the needs of electric buses. Besides, 1,156 charging and changing stations and 14,900 charging piles have been built. In the catering industry, electricity substitution will be implemented actively in the next few years. 
Many researches have focused on driving forces analysis of energy consumption using different methods. Li Y et al [4] applied the logarithmic mean Divisia index (LMDI) method to analyze the driving forces of the consumption of water and energy in China. Shumin Chen [5] studied the influence of GDP, industrialization level, population, urbanization rate and international trade on power consumption based on multiple regression analysis. Wang Bin et al [6] decomposed the driving factors of power consumption into five factors, including the change of GDP, industrial structure, industrial power consumption intensity, population size, and per capita power consumption based on the exponential decomposition method, and predicted the total power demand of Beijing in the future. Hong J, Lu Y et al [7, 8] applied structural decomposition analysis to explore the driving forces behind the energy increase in the China's construction industry. Liu X et al [9] applied a joint decomposition approach, introducing an index decomposition analysis (IDA) method into a production theoretical decomposition analysis (PDA) to explore the driving factors behind energy consumption in China. However, the LMDI method is widely used because of its advantage of overcoming the influence of residual value. For example, Shi-Chun $\mathrm{Xu}$ et al [10] applied LMDI to find factors influencing $\mathrm{CO}_{2}$ emissions due to energy consumption in China and decomposed the factors into energy structure, energy intensity, industry structure, economic output, and $p$ opulation scale effects. Lima F et. al [11] resorted to LMDI decomposition method to explore the changes in the aggregate energy consumption by decomposing the factors into activity, structure and intensity. Achour $\mathrm{H}$ et al [12] decomposed the influencing factors into energy intensity, transportation structure effect, transportation intensity effect, economic output, and population scale effect to explore the drivers of energy consumption in Tunisian transportation sector based on the LMDI method. Besides, the power consumption is also decomposed into seven effects, such as population effect, economic scale effect, industrial structure effect, industrial power consumption intensity, urbanization level effect, residents' consumption effect and residents' power consumption intensity to explore the driving forces of power consumption in Hebei province [13].

However, in the literatures on the analysis of factors affecting energy consumption or power consumption, the factors are mainly divided into economic scale effect, industrial structure effect, population effect and energy intensity effect. Therefore, electricity substitution effect (or energy structure effect) is introduced in this paper to explore driving forces of total power consumption in Beijing 's final energy consumption sectors, which fills the research gap on the driving forces analysis on electricity consumption. Besides, this paper also applied the long-term energy alternative planning model (LEAP) to calculate the power consumption in final sectors based on scenario analysis. Quantitative and qualitative analysis methods are combined to predict the future power consumption of Beijing in this paper

This paper consists of five sections. The remaining parts are organized as follows. Section 2 mainly presents the methodology including LMDI decomposition method and LEAP scenario analysis method. Section 3 provides the decomposition results and discussion. Then, different scenarios are set up and the scenario results are analyzed in Section 4. Finally, section 5 summarizes the conclusions and makes some policy implications.

\section{Methodology and Database}

\subsection{LMDI Decomposition Method}

Factor decomposition method is usually used to figure out and analyze the factors that affecting energy consumption and carbon emissions, which is in favor of formulating reasonable policy measures to control energy consumption and carbon emissions. The two main methodological approaches for the decomposition analysis are Structural Decomposition Analysis (SDA) and Index Decomposition Analysis (IDA), which are compared with each other in their methodological and application viewpoints by some researches such as Wang $\mathrm{H}$ et al [14]. SDA is based on the final demand and input data of different departments, including two-level decomposition and input-output method. IDA can decompose the change of the target variable into the product of several influence indexes, and then calculate the contribution degree of different influence factors by assigning certain weight.

The logarithmic mean Divisia index (LMDI) method is performed by Divisia decomposition for further processing, and the logarithmic average formula is introduced to calculate the index weight based on Kaya identity, which has the advantage of overcoming the influence of residual value, negative value and zero value [15]. The LMDI method consists of two types: multiplicative decomposition and additive decomposition, and results of the two methods are consistent and homogeneous [16]. Therefore, additive decomposition method is applied in this paper to analyze the factors affecting power consumption in Beijing. Besides, the total power consumption ( $E C$ ) is decomposed into two parts, industrial power consumption ( $\left.E C^{\text {industry }}\right)$ and residential power consumption ( $E C$ resident $)$ due to the different characteristics of influencing factors in industrial and residential power consumption. In time [ $t, T]$, the amount of change in total power consumption can be expressed by formula (1).

$$
\begin{aligned}
& \triangle E C=E C^{T}-E C^{t} \\
& =E C_{\text {industry }}^{T}-E C_{\text {industry }}^{t}+E C_{\text {resident }}^{T}-E C_{\text {resident }}^{\mathrm{t}} \\
& =\Delta E C_{\text {industry }}+\Delta E C_{\text {resident }}
\end{aligned}
$$

The electricity consumption in industry sector is decomposed into the product of four factors, such as industrial electricity substitution effect, industrial energy intensity effect, industrial structure effect, economic scale effect. Similarity, the electricity consumption in residents is decomposed into the product of residential electricity substitution effect, residential energy intensity effect, population structure effect 
and population scale effect, which is shown in equation (2).

$$
\begin{aligned}
& E C_{\text {industry }}^{t}=\sum_{j=1}^{3} E C_{j}^{t}=\sum_{j=1}^{3} \frac{E C_{j}^{t}}{T E C_{j}^{t}} \times \frac{T E C_{j}^{t}}{G D P_{j}^{t}} \times \frac{G D P_{j}^{t}}{G D P^{t}} \times G D P^{t} \\
& =\sum_{j=1}^{3} E T_{j}^{t} \times E I_{j}^{t} \times I S_{j}^{t} \times G D P^{t} \\
& E C_{\text {resident }}^{t}=\sum_{m=1}^{2} E C_{m}^{t}=\sum_{m=1}^{2} \frac{E C_{m}^{t}}{T E C_{m}^{t}} \times \frac{T E C_{m}^{t}}{P_{m}^{t}} \times \frac{P_{m}^{t}}{P^{t}} \times P^{t} \\
& =\sum_{m=1}^{2} E T_{m}^{t} \times E I_{m}^{t} \times P S_{m}^{t} \times P^{t}
\end{aligned}
$$

Where, EC refers to the total electricity consumption, $E C_{j}$ indicates the electricity consumption of the $j$-th industry sector, namely primary industry $(j=1$; refers to agriculture, forestry, animal husbandry, fishing and water conservation), secondary industry $(j=2$; refers to mining and quarrying, manufacturing, production and supply of electricity, water and gas, and construction), tertiary industry ( $j=3$; refers to other industry such as transport, storage and post, wholesale, retail trade and hotel, restaurants), $E C_{m}$ represents resident power consumption, urban residents' $(m=1)$ and rural residents' $(m=2)$ respectively; $T E C_{j}, T E C_{m}$ represents the total energy consumption of the $j$-th sector and $m$-th sector respectively (consumption of coal, oil, natural gas, heat, electricity, and other forms of energy); $G D P_{j}$ refers to the added value of GDP in sector $j$; $G D P$ is total gross domestic product; $P_{m}$ refers to population size in sector $m ; P$ is total population. The specific meanings of each influencing factor are shown in Table 1.

Table 1. Decomposed influencing factors of total power consumption.

\begin{tabular}{lll}
\hline Influencing factor & Indication & Specific meaning \\
\hline Industrial electricity substitution effect & $E T_{j}$ & Ratio of power consumption to total energy consumption of the $j$-th sector \\
Industrial energy intensity effect & $E I_{j}$ & The total energy consumed per unit of GDP in industry $j$ \\
Industrial structure effect & $I S$ & Ratio of GDP generated by industry $j$ to the total GDP of the whole society \\
Economic scale effect & $G D P$ & Total gross domestic product \\
Residential electricity substitution effect & $E T_{m}$ & Ratio of power consumption to total energy consumption of the $m$-th sector \\
Residential energy intensity effect & $E I_{m}$ & Total energy consumption per capita in $m$ sector \\
Population structure effect & $P S$ & The proportion of the population in sector $m$ to the total population \\
Population scale effect & $P$ & Total population
\end{tabular}

The change in the total electricity consumption (EC) from the base year $\mathrm{t}$ to the target year $\mathrm{T}$ is completely decomposed as the formula (3).

$$
\begin{aligned}
& \Delta E C_{\text {indatay }}=\Delta E T_{j}+\Delta E I_{j}+\Delta I S+\Delta G D P \\
& \Delta E C_{\text {rsidat }}=\Delta E T_{m}+\Delta E I_{m}+\Delta P S+\Delta P \\
& \Delta E C=\Delta E T_{j}+\Delta E I_{j}+\Delta I S+\Delta G D P+\Delta E T_{m}+\Delta E I_{m}+\Delta P S+\Delta P
\end{aligned}
$$

Where $\triangle E C$ indicates the total amount of total electricity consumption change within time interval [t, T]; $\Delta E T_{j}$ denotes the amount of total electricity consumption change due to the electricity substitution in industrial sectors; $\triangle E I{ }_{j}$ denotes the amount of total electricity consumption change due to the energy intensity in industrial sectors $\Delta I S$ denotes the amount of total electricity consumption change due to adjustment of industrial structure; $\triangle G D P$ implied the amount of total electricity consumption change due to economic scale; similarly, $\triangle E T_{m}, \Delta E I_{m}, \Delta P S, \Delta P$ indicates the amount of total electricity consumption change caused by electricity substitution in residents, energy intensity in residents, population structure adjustment and total population respectively. According to the LMDI decomposition principle, each affecting factor can be expressed as equations (4) and (5).

$$
\begin{aligned}
\Delta E C_{E T_{j}} & =\sum_{j=1}^{3} w_{j} \ln \left(\frac{E T_{j}^{T}}{E T_{j}^{t}}\right) \\
\Delta E C_{E I_{j}} & =\sum_{j=1}^{3} w_{j} \ln \left(\frac{E I_{j}^{T}}{E I_{j}^{t}}\right) \\
\Delta E C_{I S} & =\sum_{j=1}^{3} w_{j} \ln \left(\frac{I S_{j}^{T}}{I S_{j}^{t}}\right) \\
\Delta E C_{G D P} & =\sum_{j=1}^{3} w_{j} \ln \left(\frac{G D P^{T}}{G D P^{t}}\right) \\
\Delta E C_{E T_{m}} & =\sum_{m=1}^{2} w_{m} \ln \left(\frac{E T_{m}^{T}}{E T_{m}^{t}}\right) \\
\Delta E C_{E I_{m}} & =\sum_{m=1}^{2} w_{m} \ln \left(\frac{E I_{m}^{T}}{E I_{m}^{t}}\right) \\
\Delta E C_{P} & =\sum_{m=1}^{2} w_{m} \ln \left(\frac{P^{T}}{P^{t}}\right) \\
\Delta E C_{P S} & =\sum_{m=1}^{2} w_{m} \ln \left(\frac{I S_{m}^{T}}{I S_{m}^{t}}\right)
\end{aligned}
$$


The weights $w_{j}, w_{m}$ in the above formulas can be calculated by formula (6).

$$
\begin{gathered}
w_{j}=\left(E C_{j}^{T}-E C_{j}^{t}\right) /\left(\ln E C_{j}^{T}-\ln E C_{j}^{t}\right) \\
w_{m}=\left(E C_{m}^{T}-E C_{m}^{t}\right) /\left(\ln E C_{m}^{T}-\ln E C_{m}^{t}\right)
\end{gathered}
$$

\subsection{LEAP Scenario Analysis Method}

LEAP is a medium and long-term energy alternative planning model developed by Stockholm Environmental Institute Boston, which has four parts: energy demand module, energy transformation module, production module and resource module [17]. The final energy demand module calculates the demand for various kinds of energy according to the activity level, the corresponding energy intensity and energy consumption types of various activities. In this model, the final energy demand module has a relatively complete function, which can not only input the technical data of specific energy-using equipment to make a detailed analysis of the terminal energy-using technology, but also analyze the changing trend of departmental energy consumption according to the input macroeconomic parameters such as GDP and total population. In addition, this model has the core function of scenario analysis, which can help us easily conduct scenario analysis. Many researchers studied the long-term forecasting of energy supply and demand by scenario analysis based on LEAP because of its powerful accounting ability and its flexible application [18-21].

In the energy consumption forecast of end-demand sector in LEAP, the total energy demand of primary energy and secondary energy can be calculated as the product of the total activity level (a measure of social and economic activity) and energy intensity (the average energy consumption of some device or end-use per unit of activity) at each given branch, scenario and year [22]. The calculation formula is shown in bellow equation (7).

$$
\begin{aligned}
& D_{f}=\sum_{X} \sum_{i} L_{X, i} \times I_{X, i} \times S_{f} \\
& D_{S}=\sum_{X} \sum_{i} L_{X, i} \times I_{X, i} \times S_{S}
\end{aligned}
$$

Where, $D_{f}$ indicates total primary energy consumption of type $f$ energy in end-demand sector; $D_{s}$ represents total secondary energy consumption of type $S$ energy in end-demand sector; $L_{X, i}$ is the activity level of subsector $i$ in sector $X ; I_{X, i}$ is the energy intensity; $S_{S}$ is the share of type $S$ energy in total energy demand in subsector $i$ of sector $X$.

In this paper, the electricity consumption in end-demand sector of Beijing is forecasted based on the second formula in equation (7).

\subsection{Database and Analysis}

Economic data, demographic data and energy consumption data are required for the analysis in this paper. Specifically, the total power consumption and energy consumption in each final demand sector, industrial added value of each sector, GDP, total population of urban and rural data from 2007 to 2017 are selected because of the data availability, which are from Beijing Statistical Yearbook. In order to eliminate the influence of price factor, the GDP and the added value of each industry sector are converted according to the constant price in 2007 as the base period.

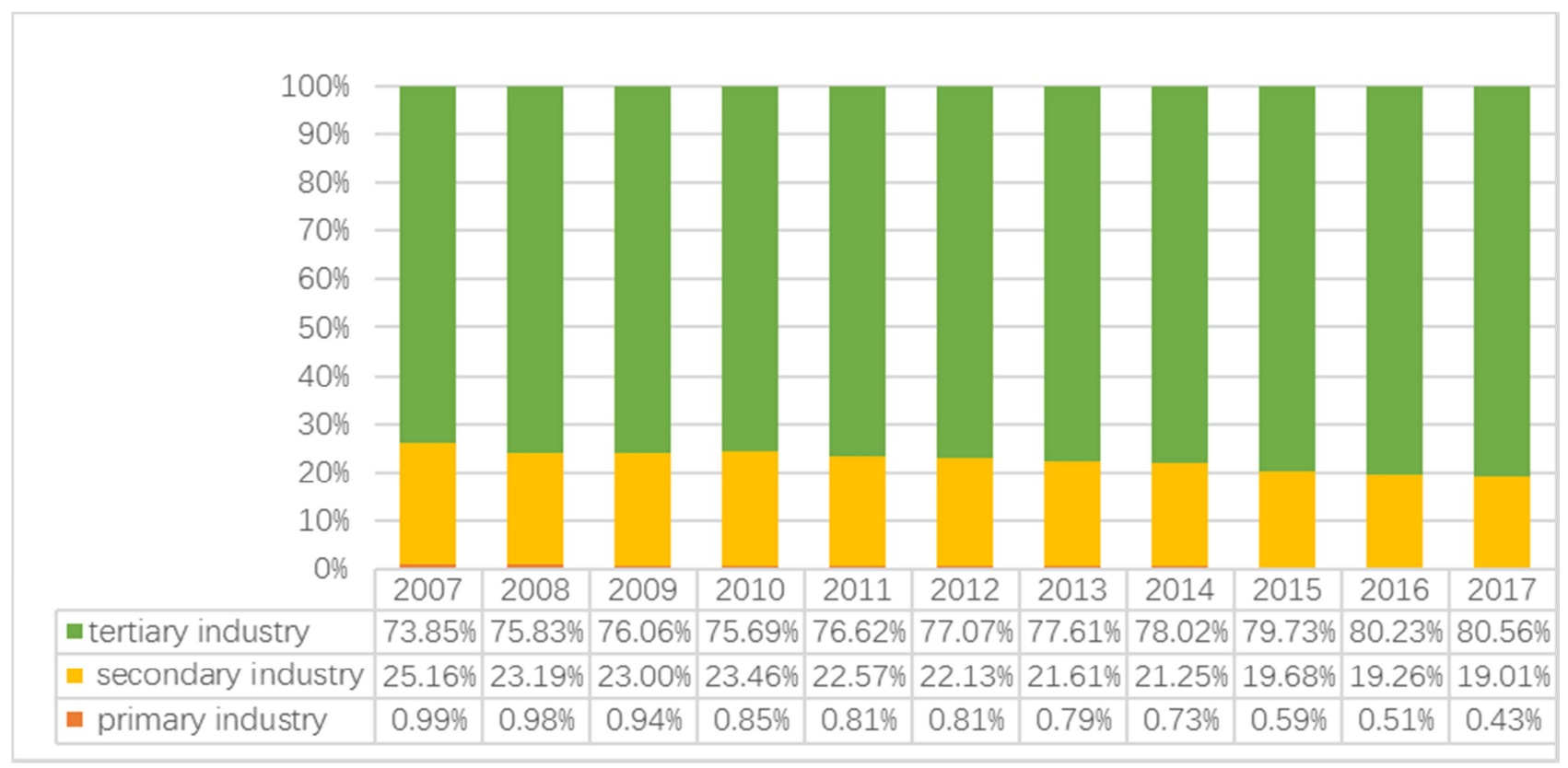

Figure 1. The added value proportion changes of each industry sector (unit:\%).

The ratio of the added value in three main industries to GDP changed from 0.99: 25.16: 73.8 to 0.43 : 19.01: 80.56 during 2007-2017 (Figure 1). The proportion of urban and rural population in the total population changed from 84.5: 15.5 to 86.45: 13.55 during 2007-2017 (Figure 3). 


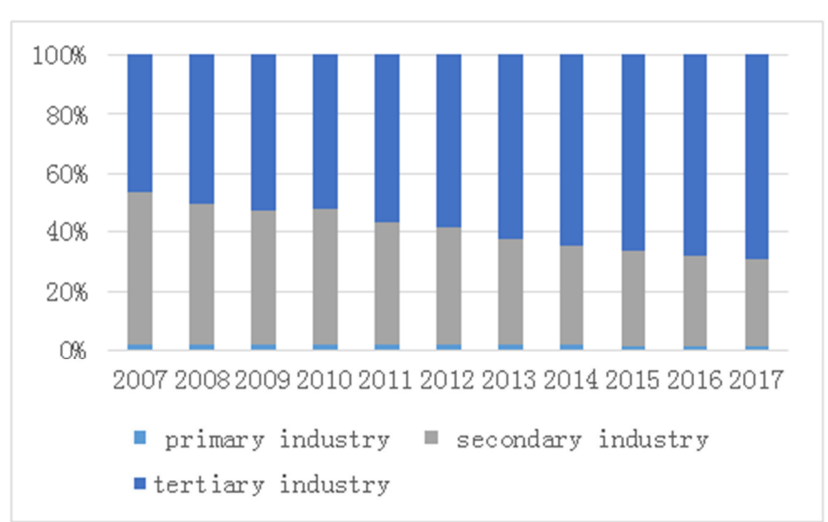

Figure 2. Energy consumption proportion changes of each industry (unit:\%).

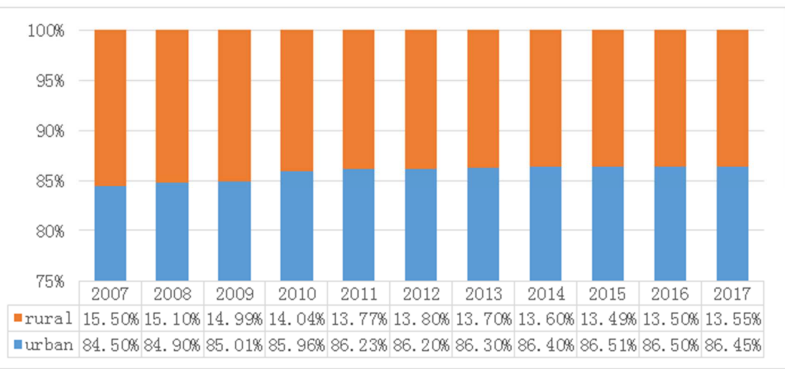

Figure 3. Population proportion changes of urban and rural (unit:\%).

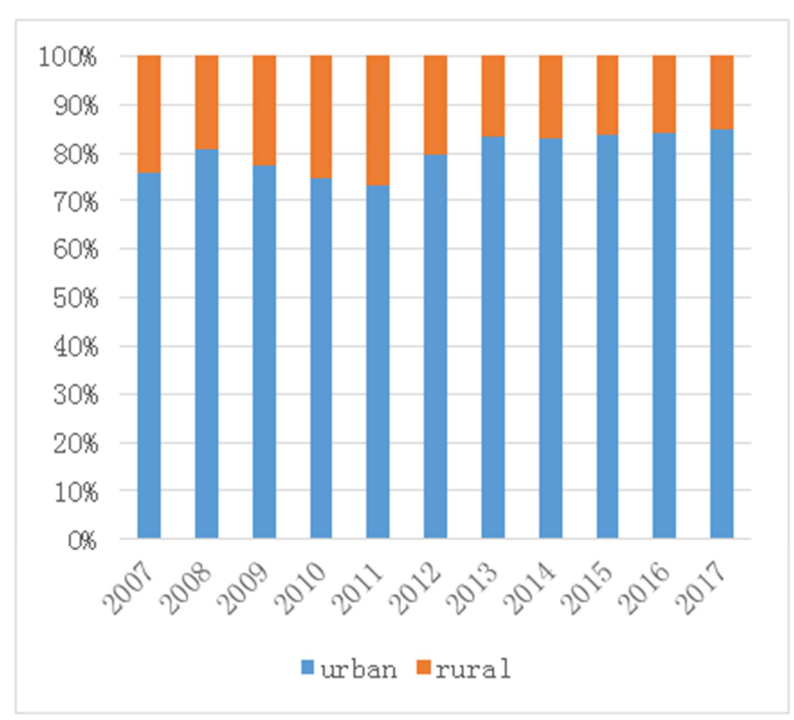

Figure 4. Energy consumption proportion changes of urban and rural (unit:\%).

A comparison of Figure 1 and Figure 2 reveals certain consistence between energy consumption and production structures, which indicates the relationship between industrial structure adjustment and energy consumption. Similarly, the comparison of Figure 3 and Figure 4 reveals certain consistence between energy consumption and population structure.

According to the electricity and energy consumption data in each sector, the ratio of electricity consumption to total energy consumption in each sector can be calculated as Figure 5, which depicts that the ratio of electricity to total energy consumption changes in primary and secondary industry are more obvious than other sector and both shows obvious increasing trend. Besides, the ratio of electricity to total energy consumption in tertiary industry increases steadily and slowly. However, in rural residents, the proportion of electricity consumption to total energy consumption increases visibly from 2007 to 2011 and shows a down trend in 2012, then presents the increasing trend from 2013. This is because the electricity consumption and energy consumption of rural residents dropped sharply in 2012. Urban residents show a rising trend of fluctuation across periods.

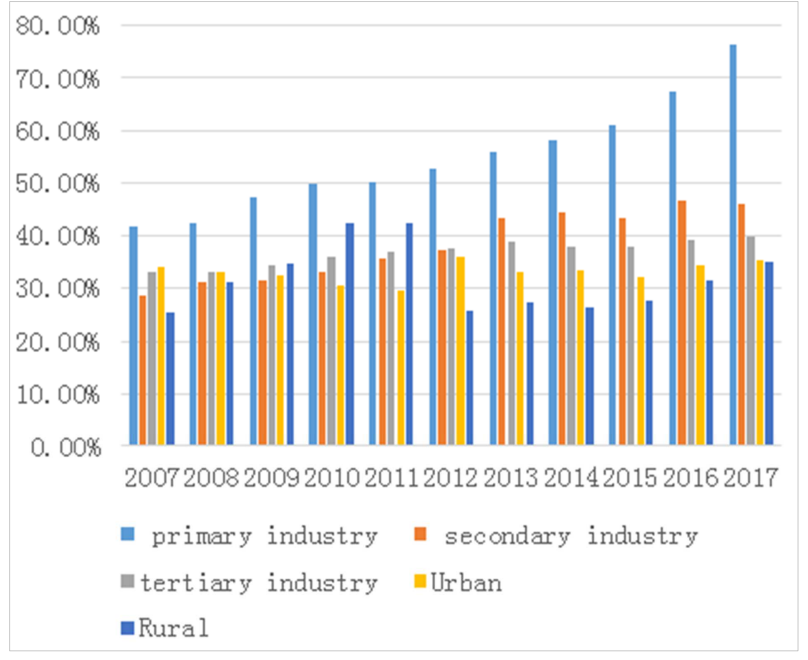

Figure 5. The ratio of electricity to total energy consumption changes in each sector (unit:\%).

\section{Results and Discussion}

\subsection{Decomposition Results and Discussion}

Based on the additive LMDI decomposition method, the influencing factors of total power consumption are decomposed into two parts (industry and residents) by using the formula (1) to formula (6), and the relevant economic, demographic and energy consumption data of Beijing from 2007 to 2017. The decomposition results are shown in Table 2, Table 3, Figures 6-8.

Table 2 and table 3 depict the results of each decomposition factor for power consumption in Beijing final sector by rolling base year, which shows that power consumption by the final consumption sector in 2017 increased by 105.31 thousand tons of standard coal as compared to 2016. As for the decomposition, power consumption increased by $17.55,48.28$, $24.42,35.77,0.034$ ten thousand tons of standard coal due to the $\triangle E T_{j}, \triangle G D P, \triangle E T_{m}, \triangle E I_{m}, \triangle P S$ effect respectively and reduced by $7.68,12.49$ and 0.58 ten thousand tons of standard coal due to $\Delta E I_{j}, \Delta I S$ and $\triangle P$ effect respectively.

Therefore, from 2007 to 2017, the industrial electricity substitution effect, economic scale effect, residential electricity substitution effect, residential energy intensity effect and population scale effect played a significant role in increasing power consumption, whereas the industrial energy intensity effect, industrial structure effect and population 
structure effect decreased power consumption in Beijing's final energy consumption sector. In 2013, 2014 and 2015, the total power consumption by the three main industry sectors decreased in comparison to their respective previous years. In 2012-2013, power consumption due to industrial energy intensity effect, industrial structure effect reduced by 233.22 and 11.65 ten thousand tons of standard coal, whereas the industrial electricity substitution effect and economic scale effect increased the power consumption. However, in 20132014 and 2014-2015, the industrial energy intensity effect increased power consumption, while the industrial electricity substitution effect played a role in reducing it.

Figure 6 depicts the decomposition results of power consumption by industry sector under each factor effect. The industrial electricity substitution effect is the largest positive driving factor to increase power consumption in industry sector, except for in 2013-2014 and 2014-2015 owing to the influence of industrial energy intensity effect. Economic scale effect is the second positive driving factor to increase power consumption in industry sector, except for in 2008-2009 owing to 2008 international financial crisis. However, industrial energy intensity effect largely contributed to decrease total electricity consumption by industry sector except 2008-2009, 2013-2014 and 2014-2015. After 2008 international financial crisis, industrial energy intensity substantially improved. Industrial structure effect is the second largest negative driving force to decrease total power consumption by industry sector except 2009-2010, which indicates that the adjustment of industrial structure can decrease power consumption of Beijing. In 2009-2010, a large investment was made in the secondary industry, resulting in the transition to energy intensive industries.

Table 2. Annual contribution value of each decomposition factor to total electricity consumption by industry (unit: Ten thousand tons standard coal).

\begin{tabular}{|c|c|c|c|c|c|c|c|}
\hline Year Interval & $\triangle E C$ & $\Delta E C_{\text {resident }}$ & $\Delta E C_{\text {industry }}$ & $\Delta E T_{j}$ & $\Delta E I_{j}$ & $\Delta I S$ & ${ }_{\triangle} G D P$ \\
\hline $2007-2008$ & 97.79 & 28.9 & 68.88 & 68.76 & -19.40 & -39.67 & 59.19 \\
\hline 2008-2009 & 115.96 & 35.01 & 80.95 & 42.30 & 58.90 & -5.06 & -15.19 \\
\hline 2009-2010 & 213.6 & 28.44 & 185.17 & 91.44 & -7.16 & 5.78 & 95.11 \\
\hline $2010-2011$ & 78.55 & 16.47 & 62.08 & 82.73 & -120.78 & -20.58 & 120.71 \\
\hline 2011-2012 & 134.57 & 45.87 & 88.7 & 59.72 & -4.84 & -9.10 & 42.92 \\
\hline $2012-2013$ & -41.16 & -15.15 & -26 & 160.68 & -233.22 & -11.65 & 58.19 \\
\hline 2013-2014 & 21.69 & 26.04 & -4.34 & -12.50 & 8.81 & -10.41 & 9.76 \\
\hline $2015-2016$ & 158.56 & 52.1 & 106.45 & 108.61 & -16.74 & -15.34 & 29.92 \\
\hline $2016-2017$ & 105.31 & 59.65 & 45.66 & 17.55 & -7.68 & -12.49 & 48.28 \\
\hline Cumulative value (2007-2017) & 861.6 & 279.24 & 582.36 & 600.47 & -328.61 & -158.03 & 468.55 \\
\hline
\end{tabular}

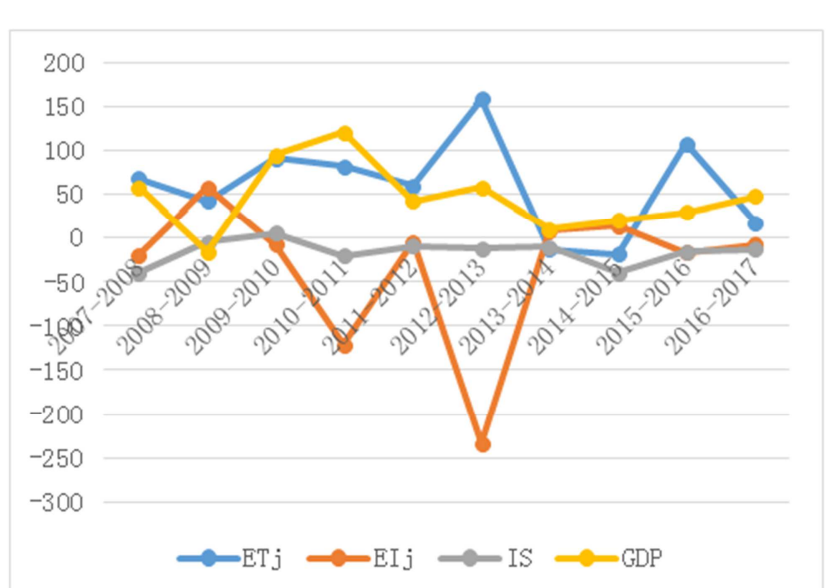

Figure 6. Annual contribution value of each decomposition factor to total electricity consumption by industry (unit: Ten thousand tons standard coal).

Figure 7 depicts the decomposition results of power consumption by resident under each factor effect. Residential energy intensity effect has the largest contribution to increase total electricity consumption by resident in Beijing during 2007-2017. It is because of the improvement of people's living standards that Beijing's per capita energy consumption by resident has continued to increase in those years. Population scale effect also has a positive driving effect on the total power consumption by resident except 2016-2017 owing to the declination of total population in 2017 compared to the previous base year. Besides, with the slowdown of the total population growth rate, the contribution value of total population also shows an obvious downward trend. This is mainly due to Beijing's points-based population settlement policy in 2016 to control population size, which scores the points from nine different aspects, such as legal and stable employment, occupation area, educational background, innovation and entrepreneurship, law-abiding record, age, tax payment and so on.

The power consumption due to the residential electricity substitution effect fluctuates across periods, which depicts an inconsistent pattern. However, the residential electricity substitution effect indicates large positive values in 2015-2016 and 2016-2017. After the big fluctuation in 2012, the residential electricity substitution effect substantially improved, which also has a strong relationship with the active measures implemented in Beijing residents demand side, such as replacement of coal and oil with electricity. Therefore, power energy replaceable role will be further strengthened in the next few years with the promotion of energy consumption structure transformation.

Population structure effect is the only negative driver to decrease the total power consumption by resident with the cumulative contribution value -6.25 . However, the population structure effect indicates relatively large positive values in 2016-2017 because of the "non-capital function" relief policy, which refers to the population in urban centers is moving toward the outside surrounding areas. 
Table 3. Annual contribution value of each decomposition factor to total electricity consumption by resident (unit: Ten thousand tons standard coal).

\begin{tabular}{llllllll}
\hline Year Interval & $\Delta E C$ & $\Delta E C_{\text {industry }}$ & $\Delta E C_{\text {resident }}$ & $\Delta E T_{m}$ & $\Delta E I_{m}$ & $\Delta P S$ & $\Delta P$ \\
\hline $2007-2008$ & 97.79 & 68.88 & 28.9 & 5.56 & 5.24 & -0.35 & 18.45 \\
$2008-2009$ & 115.96 & 80.95 & 35.01 & 2.90 & 14.34 & -0.18 & 17.95 \\
$2009-2010$ & 213.6 & 185.17 & 28.44 & 5.42 & 5.78 & -3.97 & 21.19 \\
$2010-2011$ & 78.55 & 62.08 & 16.47 & -11.07 & 17.39 & -1.83 & 11.99 \\
$2011-2012$ & 134.57 & 88.7 & 45.87 & 15.88 & 18.84 & 0.13 & 11.03 \\
$2012-2013$ & -41.16 & -26 & -15.15 & -32.30 & 7.03 & -0.04 & 10.17 \\
$2013-2014$ & 21.69 & -4.34 & 26.04 & 5.11 & 12.78 & -0.02 & 8.16 \\
$2014-2015$ & -23.27 & -25.17 & 1.91 & -13.98 & 11.65 & -0.03 & 4.26 \\
$2015-2016$ & 158.56 & 106.45 & 52.1 & 37.68 & 13.85 & 0.004 & 0.57 \\
$2016-2017$ & 105.31 & 45.66 & 59.65 & 24.42 & 35.77 & 0.034 & -0.58 \\
Cumulative value (2007-2017) & 861.6 & 582.36 & 279.24 & 39.62 & 142.67 & -6.25 & 103.19 \\
\hline
\end{tabular}

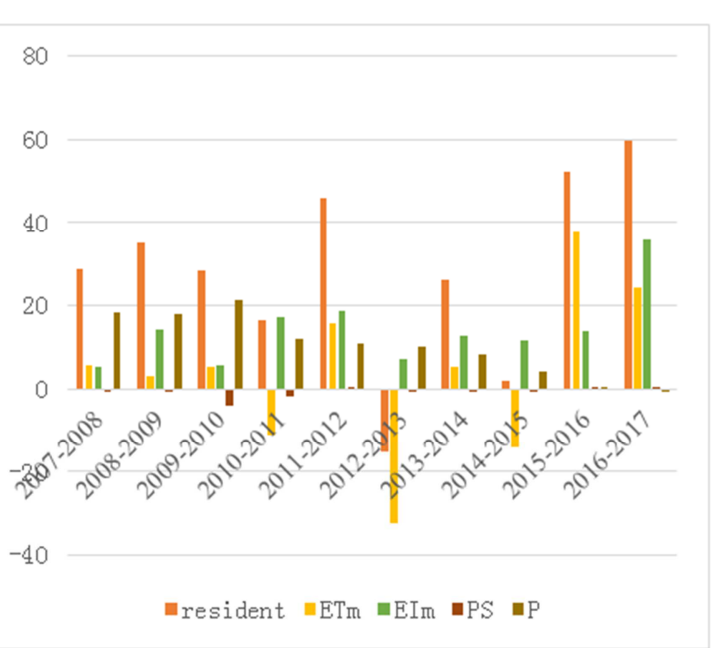

Figure 7. Annual contribution value of each decomposition factor to total electricity consumption by resident (unit: Ten thousand tons standard coal).

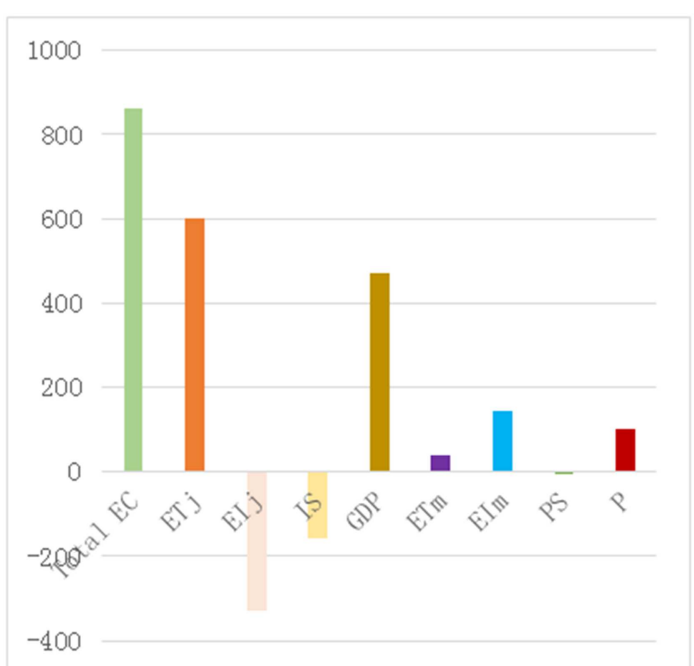

Figure 8. Cumulative contribution values of each factor to electricity consumption entire periods (unit: Ten thousand tons standard coal).

\subsection{Conclusions}

The cumulative results of the additive factor decomposition during the entire periods are given in the last low of Table 2 and Table 3 and depicted in Figure 8. As compared to 2007, electricity consumption in 2017 increased by 861.6 ten thousand tons of standard coal, of which 600.47 ten thousand tons of standard coal increased due to the industrial electricity substitution effect, 468.55 ten thousand tons of standard coal increased due to economic scale effect, 39.62 ten thousand tons of standard coal increased due to residential electricity substitution effect, 142.67 ten thousand tons of standard coal increased due to residential energy intensity effect, 103.19 ten thousand tons of standard coal increased due to population scale effect, and $328.61,158.03,6.25$ ten thousand tons of standard coal decreased due to the industrial energy intensity effect, industrial structure effect and population structure effect respectively. Over the periods, industrial electricity substitution effect and industrial energy intensity effect moved in opposite directions. The industrial electricity substitution effect decreased when the industrial energy intensity effect increased and vice versa (see Figure 6).

From the decomposition results and discussion above, the major conclusions are presented as following. Firstly, the industrial electricity substitution effect made the largest contribution to increase power consumption in Beijing's final energy consumption sector, followed by economic scale effect, residential energy intensity effect, population scale effect and residential electricity substitution effect. However, the industrial energy intensity effect, industrial structure effect and population structure effect made the contribution to decrease the power consumption (Figure 8).

Secondly, the change in power consumption pattern was observed during 2012-2013. During 2012-2013, total power consumption in Beijing decrease evidently, which is due to vigorously implement projects, such as replacing and conserving energy. Besides, the industrial energy intensity effect is more evident than the industrial electricity substitution effect, so they jointly contributed to the power consumption. After 2015, the industrial electricity substitution effect is evident. This means that industrial electricity substitution effect and industrial energy intensity effect have some relationship to influence each other and contribute to power consumption jointly.

Thirdly, the factor decomposition by resident shows that the change of some decomposition factor reflects the effect of policy implemented in Beijing, such as energy consumption structure transformation policy, "non-capital function" relief policy and points-based population settlement policy. Therefore, it is very important to analyze the future direction and trend of those kind of policy to forecast the future power consumption in Beijing final energy consumption sector. 


\section{Scenario Setting and Results Analysis}

\subsection{Scenario Setting}

The time period of the analysis spans the years 2017 to 2030 , with 2017 as the baseline year and 2030 as the end year. The driving factors of the power consumption comprise economic growth, population size, adjustment of industrial structure, improvement of urbanization, the change for the consumption pattern (energy consumption structure transition). Two major end-use sectors are incorporated in the model: industry sector (subsector: primary industry, secondary industry, tertiary industry) and resident sector (subsector: urban resident and rural resident).

Based on the following statement, scenario parameters in Business as usual (BAU) are set as the Table 4.

The goal of adhering to the production space intensive and efficient and building a sophisticated economic structure are presented in Beijing's overall plan for the city (2016-2035) [23]. Specifically, high-end industries of the value chain will be focused on, and modern services such as finance, technology, information and business services will be promoted, while transformation and upgrading of traditional industries will be further strengthened. Therefore, Beijing will take action to strengthen the strategic readjustment of economic structure and vigorously develop the "high-tech" industry. Therefore, the economic structure of Beijing continues to shift to the tertiary industry and is predicted by historical trend.

As for economic growth, the average annual rate of $6.5 \%$ in GDP is predicted in the 13th five-year plan for Beijing's national economic and social development, and the average annual rate of $6 \%$ during 2020-2025 and the average annual rate of $5.5 \%$ in $2025-2026$ is predicted referring to the literature [24]. Because of the real GDP used in this paper, average annual rate is predicted based on both the history trend and the assumption of from high speed to medium speed development in the future.

Beijing's overall plan for the city (2016-2035)[23] also sets clear targets for strictly controlling the population size with under 23 million by 2020 , and will be stable at this level for a long time after 2020. Besides, accelerating the urbanization of the rural population as well as optimizing the population distribution in city by the implementation of "non-capital function" relief policy is presented. Therefore, the urbanization rate of Beijing is predicted by historical trend and population size is constrained like city overall plan.

In "future energy 2050 planning and technology development" research proposal, the average level of electrification of China is expected to rise by 1 percentage point, and the total energy intensity will drop by $2.6 \%$ in China from 2016 to 2030 . Therefore, the share of electricity in final energy consumption in each sector is predicted based on their history trend in the Business as usual scenario. However, they are predicted based on the assumption of accelerated and slow-speed electricity substitution in final energy demand side in other scenarios, considering Beijing`s electrification promotion in industry, transportation, commerce and residential areas.

The energy intensity in each sector is predicted based on their history trend in the Business as usual (BAU) scenario. However, in other scenarios they are based on the assumption of accelerated and slow-speed energy efficient improvement in final energy demand side. Besides, secondary industry is paid more attention because of its great contribution to the total energy intensity in Beijing.

In this study, we define seven scenarios, namely Business as usual scenario (BAU), Accelerated energy efficient improvement scenario (AEI), Slow-speed energy efficient improvement scenario (SEI), Accelerated electricity substitution scenario (AES), Slow-speed electricity substitution scenario (SES), (AES and AEI), and (SES and SEI). In each scenario, the tendencies of economic development, change in industrial structure and population structure, and population growth are consistent, while the differences involve the change in energy intensity and electricity substitution. Scenario description is shown as Table 5.

Table 4. Scenario setting parameters in $B A U$.

\begin{tabular}{|c|c|}
\hline Variable & Parameters setting (2018-2030) \\
\hline$E T_{j}$ & $\begin{array}{l}\text { Primary industry }(77 \%, 78 \%, 79 \%, 80 \%, 81 \%, 82 \%, 83 \%, 84 \%, 85 \%, 86 \%, 87 \%, 88 \%, 89 \%) \\
\text { Secondary industry }(46.5 \%, 47 \%, 47.5 \%, 48 \%, 48.5 \%, 49 \%, 49.5 \%, 50 \%, 50.5 \%, 51 \%, 51.5 \%, 52 \%, 52.5 \%) \\
\text { Tertiary industry }(40 \%, 41 \%, 42 \%, 43 \%, 44 \%, 45 \%, 46 \%, 47 \%, 48 \%, 49 \%, 50 \%, 51 \%, 52 \%)\end{array}$ \\
\hline$G D P$ & The annual growth rate (real GDP) of 2.5\%during 2018-2020, $2 \%$ during $2020-2025,1.5 \%$ in $2025-2030$. \\
\hline$I S$ & $\begin{array}{l}\text { The industrial structure of the three major industries (primary: secondary: tertiary) reaches } 0.2: 12.5: 87.3 \text { in end year (2030), and other } \\
\text { scenario years are interpolated according to base year. }\end{array}$ \\
\hline$E I_{j}$ & $\begin{array}{l}\text { Energy intensity in each industry sector is estimated based on the logistic forecast function, which forecasts the future values based on a } \\
\text { fitting a logistic function to the time serios data (2007-2017) by liner regression. }\end{array}$ \\
\hline$E T_{m}$ & $\begin{array}{l}\text { Urban }(35.5 \%, 35.8 \%, 36.1 \%, 36.4 \%, 36.7 \%, 37 \%, 37.3 \%, 37.6 \%, 37.9 \%, 38.2 \%, 38.5 \%, 38.8 \%, 39.1 \%) \\
\text { Rural }(36 \%, 37 \%, 38 \%, 39 \%, 40 \%, 41 \%, 42 \%, 43 \%, 44 \%, 45 \%, 46 \%, 47 \%, 48 \%)\end{array}$ \\
\hline$P$ & According to Beijing's overall plan for the city (2016-2030), the population size is controlled at 23 million by 2030 \\
\hline$P S$ & The population structure (urban: rural) reaches $88.5: 11.5$ in end year, and other scenario years are interpolated according to base year. \\
\hline$E I_{m}$ & $\begin{array}{l}\text { Energy intensity in urban and rural residents are estimated based on the logistic forecast function, which forecasts the future values based on } \\
\text { a fitting a logistic function to the time serios data }(2007-2017) \text { by liner regression. }\end{array}$ \\
\hline
\end{tabular}


Table 5. Scenario description in all scenarios.

\begin{tabular}{ll}
\hline Scenario & Scenario description \\
\hline Business as usual scenario (BAU) & No measures taken to influence power consumption \\
$\begin{array}{l}\text { Accelerated energy efficient } \\
\text { improvement scenario (AEI) }\end{array}$ & $\begin{array}{l}\text { Energy intensity in secondary industry continues to decrease and the declination speed is faster than in BAU, } \\
\text { other sectors as BAU }\end{array}$ \\
Slow-speed energy efficient & Energy intensity in secondary industry continues to decrease and the declination speed is slower than in BAU, \\
improvement scenario (SEI) & other sectors as BAU \\
& Primary industry: Interp $(2018,77 \%, 2030,92 \%)$ \\
& Secondary industry: Interp $(2018,46.5 \%, 2030,55 \%)$ \\
Accelerated electricity substitution & Tertiary industry: Interp $(2018,40 \%, 2030,55 \%)$ \\
scenario (AES) & Urban: Interp (2030, 42\%) \\
& Rural: Interp (2030, 51\%). \\
& Primary industry: Interp (2018, 77\%, 2030, 86\%), \\
& Secondary industry: Interp $(2018,46.5 \%, 2030,50 \%)$ \\
Slow-speed electricity substitution & Tertiary industry: Interp $(2018,40 \%, 2030,49 \%)$ \\
scenario (SES) & Urban: Interp (2030, 36\%) \\
& Rural: Interp (2030, 46\%) \\
AES and AEI & Combination of AES and AEI two scenarios \\
SES and SEI & Combination of SES and SEI two scenarios \\
\hline
\end{tabular}

\subsection{Scenario Result Analysis}

Based on the methodology we mentioned and the input parameters in above section, the values of electricity consumption for all scenarios from 2018 to 2030 in Beijing are shown in Figure 9 and Figure 10. Figure 9 depicts that electricity consumption will increase steadily from 2018 to 2030 under each final demand sector in BAU scenario except for primary and secondary industry, but with different growth rates. The tertiary industry has the highest growth rate, in which the electricity consumption is expected to reach to 21327.8 thousand tons of coal equivalents by 2030 . The total electricity consumption under BAU scenario is estimated to 31280.5 thousand tons of coal equivalents by 2030 . Therefore, the tertiary industry will be the major power consumption sector with the percentage of $68.2 \%$ to total consumption in end year, followed by the urban resident sector.

\section{Energy Demand Final Units}

Scenario: BAU, Fuel: Electricity

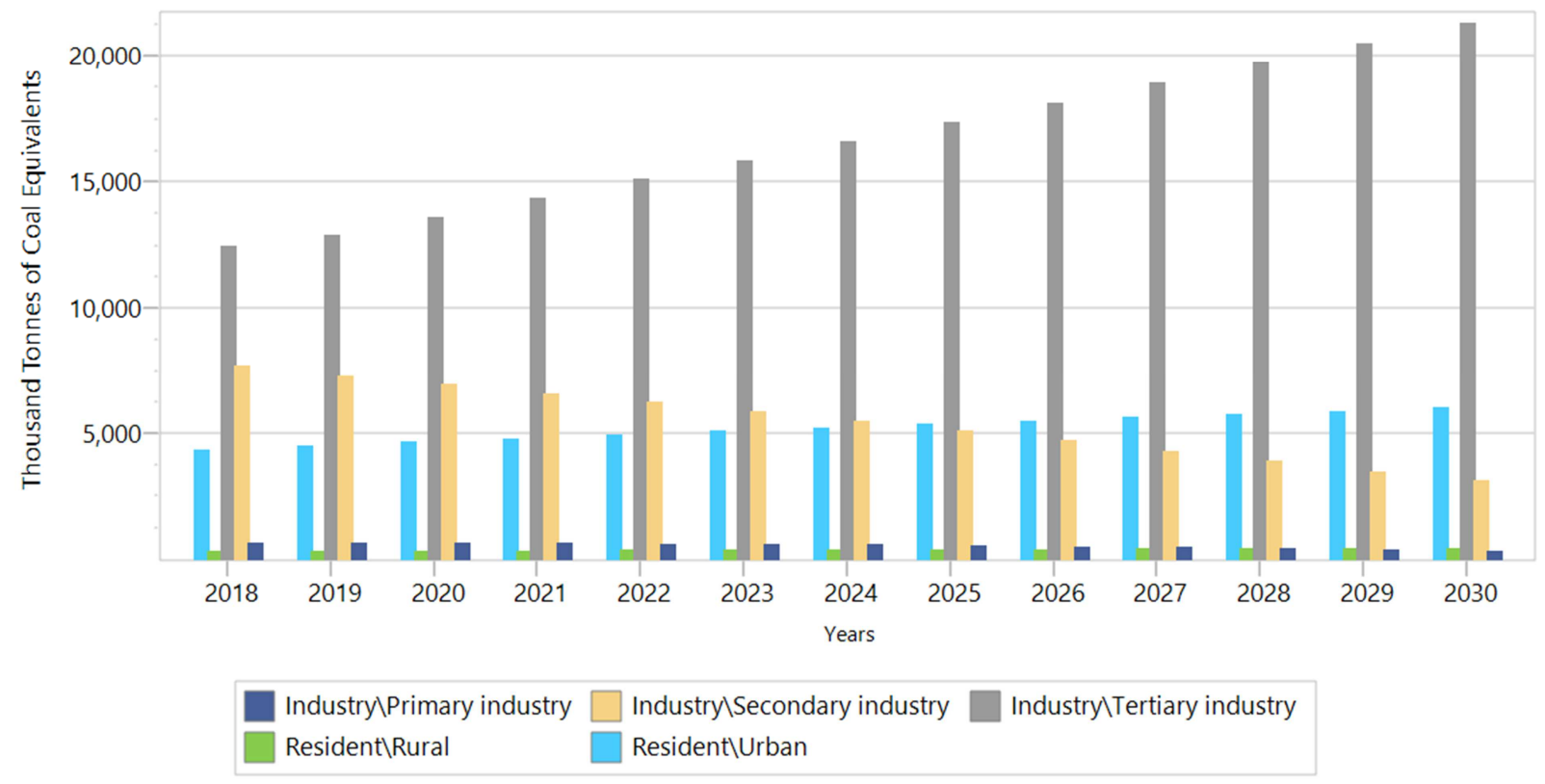

Figure 9. Electricity demand forecast of each sector in BAU scenario. 


\section{Energy Demand Final Units}

Fuel: Electricity

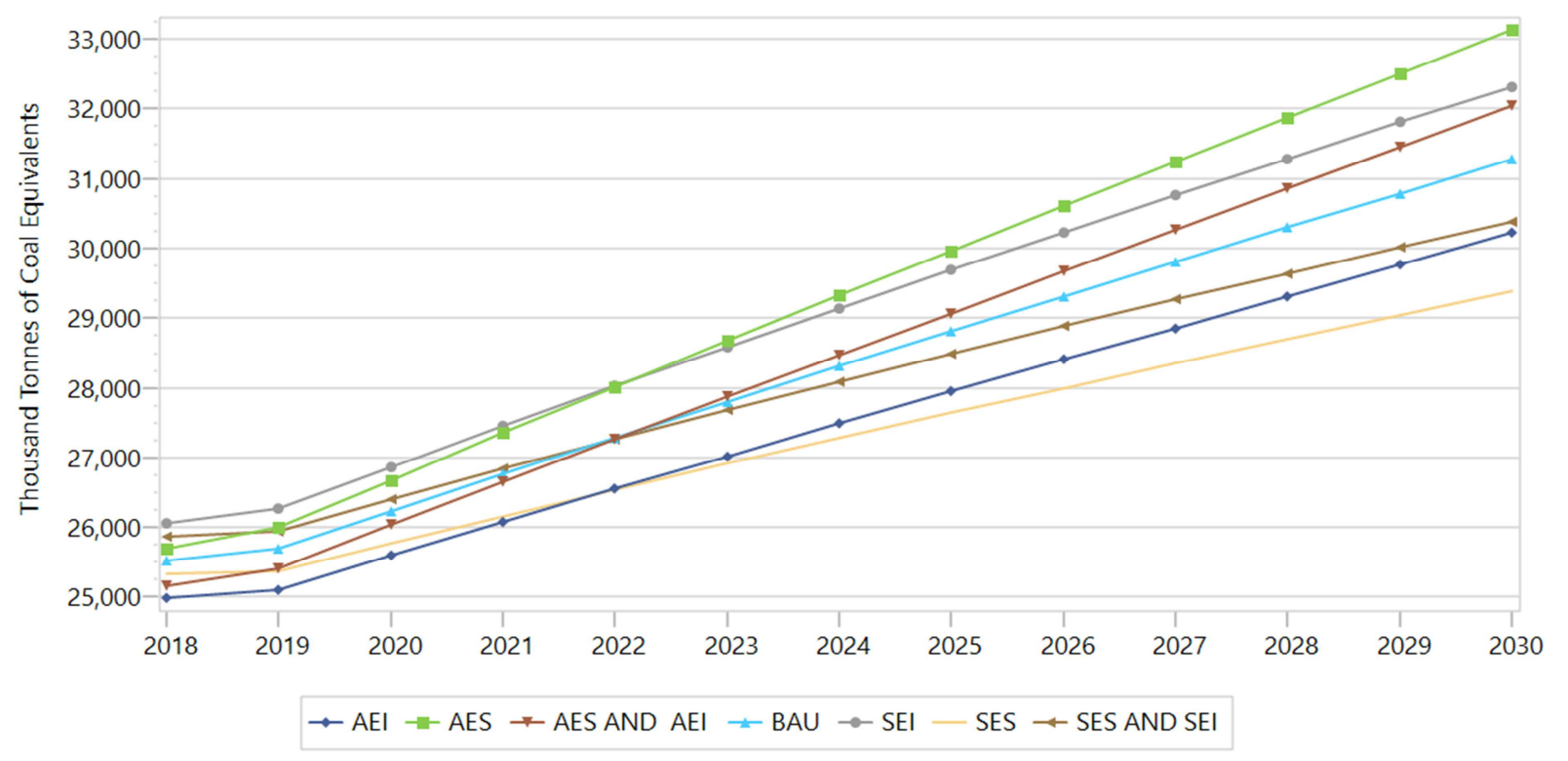

Figure 10. Total electricity demand forecast in each scenario.

Figure 10 describes the total electricity demand for BAU, AEI, SEI, AES, SES, AEI and AES, SEI and SES scenarios from 2018 to 2030 in Beijing. Under each scenario, electricity consumption will increase steadily to 2030 with different growth rates. The electricity consumption in AES scenario has the highest and in SES scenario has the lowest growth rate, where the electricity consumption is expected to reach to 33146.8 and 29383.3 thousand tons of coal equivalents by 2030 respectively. It indicates that if the electricity substitution policy implementation well in future years, the future power consumption will increase and exceed the BAU scenario, which also verify the decomposition results that electricity substitution effect has the positive contribution to power consumption. Besides, the electricity consumption under AEI and SEI scenarios are expected to reach to 30236.2 and 32324.8 thousand tons of coal equivalents by 2030 respectively, which indicates that electricity demand will be reduced if the energy efficiency of secondary industry will be improved in next few years and vice versa.

After combining two scenarios to find out the simultaneous implementation effect of electricity substitution policy and energy efficiency policy, the results show that the electricity consumption under AES and AEI, SES and SEI scenarios are expected to reach to 32052.8 and 30377.8 thousand tons of coal equivalents by 2030 respectively. This indicates that electricity consumption is growing slower than single AES scenario when electricity substitution and energy efficiency improvement accelerated, which verifies the join effect of two polices on power consumption.

\section{Conclusions and Implications}

This paper constructed the LMDI decomposition method to decompose the driving factors affecting the total electricity demand into 8 influencing factors and developed seven different scenarios to forecast the total power consumption of Beijing based on LEAP model. Here are the major conclusions: The factor decomposition results in this paper show that the industrial electricity substitution effect made the largest contribution to increase power consumption in Beijing's final energy consumption sector, followed by economic scale effect, residential energy intensity effect, population scale effect and residential electricity substitution effect. However, the industrial energy intensity effect, industrial structure effect and population structure effect made the contribution to decrease the power consumption. The industrial electricity substitution effect and industrial energy intensity effect has some relationship and can influence each other. Maybe, the implementation of electricity substitution can decrease the energy intensity and improve the total energy efficiency indirectly.

Besides, the scenario analysis results show that the energy efficiency improvement policies and electricity substitution (energy structure upgrade) policies implemented in Beijing LEAP model will have a significant impact on electricity consumption. The main conclusions are as follows. First, electricity consumption will increase steadily to 2030 with different growth rates under each development scenario in next few years and AES scenario has the highest growth rate. Second, after accelerating the energy efficient improvement, the electricity consumption in Beijing will decrease, and vice versa. Besides, after accelerating the electricity substitution, the electricity consumption in Beijing will increase, and vice versa. Finally, the power consumption in all sectors except for the primary and secondary industry are expected to increase in the future and tertiary industry will be the major power 
consumption sector, followed by the urban resident sector in future scenario years under each scenario.

The policy implications derided from this study are as follows:

(1). Actively promoting the electricity substitution in final energy consumption sector of Beijing. The factor decomposition results depict that industrial electricity substitution effect and residential electricity substitution effect have the positive driving effect to increase the electricity consumption. Besides, electricity from other cities with a high proportion of renewable energy accounts for large proportion (accounts for 65\% in 2017) in Beijing. The power generation structure of Beijing will also be further optimized in the future. Therefore, it is necessary to take policy measures to strengthen the pace of electricity substitution in final energy consumption sector and promote the optimization of energy structure in final demand side.

(2). Appropriately controlling the economic development speed and total population size. According to the decomposition results, both economic scale and population scale effect made contribution to increase the power consumption. Therefore, introducing relevant policies to control the economic growth rate and the total population size is indispensable in order to coordinate the relationship among economy, energy and environment and promote the sustainable development of Beijing. Besides, driving economic development through consumer demand in Beijing will be more preferable.

(3). Effectively improving the energy efficiency in final energy consumption sectors. Decomposition results show that the industrial energy intensity effect has the obvious negative effect on total electricity consumption, which is also verified in scenario analysis under AEI scenario and SEI scenario. Therefore, it is essential for Beijing to take some policy to guide the final consumption sectors to improve the energy efficiency by applying various kinds of demand side management and energy saving technology, for example, control management technology in the manufacturing sector, and building energy efficiency technologies in the resident sector.

(4). Positively accelerating industrial adjustment. Decomposition results show that industrial structure effect made the contribution to decrease the power consumption, which implies that the further adjustment of industrial structure can effectively reduce the total electricity demand. Therefore, it is important for Beijing to raise the ratio of the tertiary industry with high value and low carbon efficient.

\section{References}

[1] Zhao W, Cao Y, Miao B, et al. Impacts of shifting China's final energy consumption to electricity on $\mathrm{CO}_{2}$ emission reduction [J]. Energy Economics, 2018, 71: 359-369.
[2] Xiao M, Simon S, Pregger T. Scenario analysis of energy system transition-A case study of two coastal metropolitan regions, eastern China [J]. Energy Strategy Reviews, 2019, 26: 100423.

[3] Liang Y, Niu D, Zhou W, et al. Decomposition Analysis of Carbon Emissions from Energy Consumption in Beijing-Tianjin-Hebei, China: A Weighted-Combination Model Based on Logarithmic Mean Divisia Index and Shapley Value [J]. Sustainability, 2018, 10 (7): 2535.

[4] Li Y, Wang S, Chen B. Driving force analysis of the consumption of water and energy in China based on LMDI method [J]. Energy Procedia, 2019, 158: 4318-4322.

[5] Shumin Chen. Study on influencing factors of power demand in China [D]. Shandong university, 2018.

[6] Wang Bin, Xinxin zhang, Ji Ling, Yulei Xie. Power consumption driving analysis and demand prediction in Beijing [J]. China power, 2018, 51 (06): 178-184.

[7] Hong J, Li C Z, Shen Q, et al. An Overview of the driving forces behind energy demand in China's construction industry: evidence from 1990 to 2012 [J]. Renewable and Sustainable Energy Reviews, 2017, 73: 85-94.

[8] Lu Y, Cui P, Li D. Carbon emissions and policies in China's building and construction industry: evidence from 1994 to 2012 [J]. Building and Environment, 2016, 95: 94-103.

[9] Liu X, Zhou D, Zhou P, et al. Factors driving energy consumption in China: A joint decomposition approach $[\mathrm{J}]$. Journal of cleaner production, 2018, 172: 724-734.

[10] Xu, Shi-Chun, Zheng-Xia He, and Ru-Yin Long. "Factors that influence carbon emissions due to energy consumption in China: Decomposition analysis using LMDI." Applied Energy 127 (2014): 182-193.

[11] Lima F, Nunes M L, Cunha J, et al. Driving forces for aggregate energy consumption: A cross-country approach $[\mathrm{J}]$. Renewable and Sustainable Energy Reviews, 2017, 68: 1033-1050.

[12] Achour H, Belloumi M. Decomposing the influencing factors of energy consumption in Tunisian transportation sector using the LMDI method [J]. Transport Policy, 2016, 52: 64-71.

[13] Nie Jing. Power consumption prediction in hebei province under the coordinated development of beijing-tianjin-hebei region [D]. North China electric power university, 2017.

[14] Wang H, Ang B W, Su B. Assessing drivers of economy-wide energy use and emissions: IDA versus SDA [J]. Energy Policy, 2017, 107: 585-599.

[15] Ang, B. W. The LMDI Approach to decomposition analysis: Apracticalguide. EnergyPolicy 2005, 33, 867-871.

[16] Ang, B. W.; Liu, N. Handling zero values in the logarithmic mean Divisia index decomposition approach. Energy Policy 2007, 35, 238-246.

[17] Heaps C. An introduction to LEAP [J]. Stockholm Environment Institute, 2008: 1-16.

[18] Cai W, Wang C, Wang $\mathrm{K}$, et al. Scenario analysis on $\mathrm{CO}_{2}$ emissions reduction potential in China's electricity sector [J]. Energy Policy, 2007, 35 (12): 6445-6456.

[19] Huang Y, Bor Y J, Peng C Y. The long-term forecast of Taiwan's energy supply and demand: LEAP model application [J]. Energy policy, 2011, 39 (11): 6790-6803. 
[20] McPherson M, Karney B. Long-term scenario alternatives and their implications: LEAP model application of Panama' $\mathrm{s}$ electricity sector [J]. Energy Policy, 2014, 68: 146-157.

[21] Mirjat N H, Uqaili M A, Harijan K, et al. Long-term electricity demand forecast and supply side scenarios for Pakistan (20152050): A LEAP model application for policy analysis [J]. Energy, 2018, 165: 512-526.

[22] LEAP help. Activity Analysis Calculations.
https://www.energycommunity.org/Help/Demand/Activity_An alysis_Calculations.htm

[23] Beijing's overall plan for the city (2016-2035). https://max.book118.com/html/2018/1002/6041202120001221 .shtm

[24] Liu miying. Research on the decoupling relationship between economic growth and energy consumption in Beijing under the new normal [J]. China energy, 2019, 41 (01): 39-43+47 